EDITORIAL

\title{
Know Thy Ulcers!!!
}

\author{
Deepak Govil ${ }^{1}$, Praveen Kumar $\mathrm{G}^{2}$ \\ Indian Journal of Critical Care Medicine (2020): 10.5005/jp-journals-10071-23389
}

"You don't get ulcers from what you eat. You get them from what's eating you."

- Vicki Baum (An American Novelist)

The first description of acute gastrointestinal stress ulceration or disruption of mucosa was first published half a century ago. 'Despite multiple studies, pathogenesis is still not completely understood. Reduced blood flow, ischemia, and reperfusion injury of the mucosa might contribute to the development of stress ulcers. ${ }^{2}$ Stress ulcers affects the esophagus, stomach, or duodenum and may be associated with bleeding. Mechanical ventilation, coagulopathy, renal and hepatic failure, major burns, and traumatic brain injury are proven risk factors for stress ulcers and gastrointestinal bleeding. The incidence of clinically significant gastrointestinal bleeding had reduced over the years, and a recent observational study reported an incidence of $2.6 \% .^{3}$ The decrease in incidence is perceived to be due to improved resuscitation efforts and thereby reducing gastric hypoperfusion, early enteral nutrition, and pharmacological prophylaxis.

Pharmacological prophylaxis is been used in majority of critically ill patients despite absence of risk factors, no proven mortality benefit seen, and worse, it is been widely used despite multiple reported side effects with the use of them. ${ }^{4-6}$ Increased incidence of ventilator-associated pneumonia (VAP), clostridium difficile diarrhea, myocardial ischemia are few of the complications reported in the literature. Proton pump inhibitors (PPIs), histamine 2 receptor blockers, and sucralfate are commonly used; PPIs being the most frequently used drugs for prevention of stress ulcers. Proton pump inhibitors have been shown to be superior in reducing the incidence of significant gastrointestinal bleeding but have not been shown to be superior in reducing mortality when compared with other groups of drugs. ${ }^{7}$ Albeit stress ulcer prophylaxis is extensively used, guidelines for appropriate use are sparse and outdated, ${ }^{8}$ and it is heartening to see a study trying to explore and understand the practices in our country.

In an audit on practices of stress ulcer prophylaxis in intensive care unit patients published in this journal by Gupta et al., ${ }^{9} 197$ physicians with intensive care experience were interviewed with a questionnaire. Nearly two thirds of the respondents felt that stress ulcer prophylaxis should be universal and followed a local institutional-driven protocol. Similar proportion of respondents also believed that significant gastrointestinal bleeding is a common phenomenon and would start prophylaxis either on arrival to hospital or intensive care. Only a third of the respondents believed that bleeding is uncommon, and stress ulcer prophylaxis should be initiated only if risk factors exist. Mechanical ventilation, coagulopathy, use of nonsteroidal anti-inflammatory drugs were predominantly considered as risk factors for gastrointestinal bleeding, and a minority of respondents (18.3\%) also believed that diabetes as an independent major risk factor for bleeding. Large variation in initiation of prophylaxis was noted, with nearly $42.6 \%$ started when at least one risk factor is present, but a significant
${ }^{1}$ Institute of Critical Care and Anesthesia, Medanta The Medicty, Gurugram, Haryana, India

${ }^{2}$ Institute Critical Care Medicine, Medanta the Medicity, Gurugram, Haryana, India

Corresponding Author: Deepak Govil, Institute of Critical Care and Anesthesia, Medanta The Medicty, Gurugram, Haryana, India, Phone: +91 9818056688, e-mail: drdeepak_govil@yahoo.co.in

How to cite this article: Govil D, Kumar GP. Know Thy Ulcers!!! Indian J Crit Care Med 2020;24(3):153-154.

Source of support: Nil

Conflict of interest: None

proportion of physicians (43.7\%) initiated even without risk factors. Over $90 \%$ of respondents believed that initiation of early enteral feeding, within 48 hours of admission, was protective against stress ulcers.

No uniformity was found even about timing of initiation of prophylaxis. Timings varied between arrivals to hospital, as soon as mechanical ventilation was started, till up to 7 days post that. More than two thirds of the respondents believed that PPIs were the best drugs for prevention of bleeding and was preferred over histamine 2 receptor blockers and sucralfate. In total, $65 \%$ knew that use of PPI was associated with higher incidence of VAP, with $58 \%$ of respondents believed that use of PPI was associated with greatest risk of VAP when compared with other drugs and $69.5 \%$ knew about the risk of clostridium difficile diarrhea with the use of PPIs.

When questioned about the timings of stopping stress ulcer prophylaxis, $43.7 \%$ respondents said that they would stop, once the risk factors seized to exist, but the rest said they would continue either through the stay in intensive care $(35 \%)$ or throughout the stay in the hospital (21.3\%).

Although a questionnaire-based study, multiple useful findings emerge from the study, regarding understanding and practices of stress ulcer prophylaxis. First and most important of the findings is that significant proportion of respondents believed that gastrointestinal bleeding is common phenomenon, though a recent large randomized control trial showed that the incidence is $4.2 \%$ even without stress ulcer prophylaxis and its $2.5 \%$ with use of PPIs. ${ }^{10}$ Second, PPIs were believed to be better in reducing stress ulcer related bleeding over histamine 2 receptor blockers, which is similar to what has been shown in a recent meta-analysis. ${ }^{11}$ Third, PPIs were believed to be associated with higher incidence of VAP and clostridium difficile diarrhea, but a recent meta-analysis on the use of PPIs showed that risk of VAP was similar to PPIs when compared with histamine receptor blockers. ${ }^{11}$ The risk of clostridium difficile diarrhea with PPIs or gastric acid suppression by any drug in uncertain and recent large randomized control trial did not show any difference in infectious complications 
when compared with placebo. ${ }^{10,11}$ Fourth, a large variation exists regarding timing of both initiation and termination of use of pharmacological prophylaxis, with a large number of respondents wanted to start without risk factors and continue throughout the stay, despite believing in the adverse effects of the same.

Clinical significant gastrointestinal bleeding is an uncommon phenomenon, and use of stress ulcer prophylaxis can reduce this even further. The side efforts believed to be associated have not been proven in large trails. This article brings to foray an important question, about if and when to use stress ulcer prophylaxis. The answer to it is not simple, though one can consider using only when major risk factors exist and stop immediately after they seize to exist. Updated guidelines, taking into account the recent trials in need of the hour, aid the clinicians in appropriate use of the drugs with better understanding and evidence.

\section{References}

1. Skillman JJ, Silen W. Acute gastroduodenal 'stress' ulceration: barrier disruption of varied pathogenesis? Gastroenterology 1970;59(3): 478-482. DOI: 10.1016/S0016-5085(19)33734-5.

2. Sesler JM. Stress-related mucosal disease in the intensive care unit: an update on prophylaxis. AACN Advanced Critical Care 2007;18(2): 119-128. DOI: 10.1097/01.AACN.0000269254.39967.8e.

3. Krag M, Perner A, Wetterslev J, Wise MP, Borthwick M, Bendel S, et al. Prevalence and outcome of gastrointestinal bleeding and use of acid suppressants in acutely ill adult intensive care patients. Intensive Care Med 2015;41(5):833-845. DOI: 10.1007/s00134-015-3725-1.

4. Eastwood GM, Litton E, Bellomo R, Bailey MJ, Festa M, Beasley RW, et al. Opinions and practice of stress ulcer prophylaxis in australian and new Zealand intensive care units. Crit Care Resusc 2014;16(3): 170-174.

5. Miano TA, Reichert MG, Houle TT, MacGregor DA, Kincaid EH, Bowton DL. Nosocomial pneumonia risk and stress ulcer prophylaxis: a comparison of pantoprazole vs ranitidine in cardiothoracic surgery patients. Chest 2009;136(2):440-447. DOI: 10.1378/chest.08-1634.

6. Charlot $M$, Ahlehoff $O$, Norgaard $M L$, Jørgensen $C H$, Sørensen $R$, Abildstrøm SZ, et al. Proton-pump inhibitors are associated with increased cardiovascular risk independent of clopidogrel use: a nationwide cohort study. Ann Intern Med 2010;153(6):378-386. DOI: 10.7326/0003-4819-153-6-201009210-00005.

7. Alhazzani W, Alenezi F, Jaeschke RZ, Moayyedi P, Cook DJ. Proton pump inhibitors versus histamine 2 receptor antagonists for stress ulcer prophylaxis in critically ill patients: a systematic review and meta-analysis. Crit Care Med 2013;41(3):693-705. DOI: 10.1097/ CCM.0b013e3182758734.

8. ASHP therapeutic guidelines on stress ulcer prophylaxis. ASHP Commission on therapeutics and approved by the ASHP board of directors on november 14, 1998. Am J Health Syst Pharm 1999;56(4):347-379. DOI: 10.1093/ajhp/56.4.347.

9. Gupta D, Bhalotra AR, Singh R. Audit on practices of stress ulcer prophylaxis in intensive care unit patients. Indian J Criti Care Med 2020;24(3):160-167.

10. Liboriussen L, Bestle MH, Elkjær JM, Palmqvist DF, Bäcklund M, Laake $\mathrm{JH}$, et al. Pantoprazole in patients at risk for gastrointestinal bleeding in the ICU. N Engl J Med 2018;379(23):2199-2208. DOI: 10.1056/ NEJMoa1714919.

11. Alshamsi F, Belley-cote E, Cook D, Almenawer SA, Alqahtani Z, Perri $D$, et al. Efficacy and safety of proton pump inhibitors for stress ulcer prophylaxis in critically ill patients: a systematic review and metaanalysis of randomized trials. Crit Care 2016;20(1):120. DOI: 10.1186/ s13054-016-1305-6. 